\title{
Lifestyle Influence on the Content of Copper, Zinc and Rubidium in Wild Mushrooms
}

\author{
J. A. Campos, ${ }^{1}$ J. A. De Toro, ${ }^{2}$ C. Pérez de los Reyes, ${ }^{1}$ J. A. Amorós, ${ }^{1}$ and R. García-Moreno ${ }^{3}$ \\ ${ }^{1}$ Departamento de Producción Vegetal y Tecnologia Agraria, UCLM, Ciudad Real, Spain \\ ${ }^{2}$ Instituto Regional de Investigación Científica Aplicada (IRICA) and Departamento de Física Aplicada, \\ Universidad de Castilla-La Mancha, 13071 Ciudad Real, Spain \\ ${ }^{3}$ Departamento de ciencias de la Navegación y de la Tierra, Universidade da Coruña, A Coruña, Spain
}

Correspondence should be addressed to J. A. Campos, juanantonio.campos@uclm.es

Received 2 December 2011; Revised 3 February 2012; Accepted 6 February 2012

Academic Editor: Philip White

Copyright (C) 2012 J. A. Campos et al. This is an open access article distributed under the Creative Commons Attribution License, which permits unrestricted use, distribution, and reproduction in any medium, provided the original work is properly cited.

The concentration of 18 trace elements in several species of fungi (arranged in three groups: ectomycorrhizae, saprobes, and epiphytes) has been determined. The measurements were made using the methodology of X-ray fluorescence. Higher contents of $\mathrm{Cu}$ and $\mathrm{Rb}$ (with statistical support) have been found in the ectomycorrhizal species. The $\mathrm{Zn}$ content reached higher concentrations in the saprophytic species. According to the normality test and the search for outliers, the species Clitocybe maxima and Suillus bellini accumulate large amounts of $\mathrm{Cu}$ and $\mathrm{Rb}$, respectively, so that both can be named as "outliers." The leftwards displacement of the density curves and their nonnormality are attributed to the presence of these two species, which exhibit hyperaccumulation skills for $\mathrm{Cu}$ and $\mathrm{Rb}$, respectively. Regarding $\mathrm{Zn}$ absorption, no particular species were classified as outlier; therefore it can be assumed that the observed differences between the different groups of fungi are due to differences in their nutritional physiology.

\section{Introduction}

Fungi are vital to ecosystem health as they play crucial roles in the geochemical cycles, element mobilization, and organic matter decomposition. As mycorrhizas they can improve plant growth by increasing uptake of nutrients, and as saprobes they are related to the recycling of biomass mineral constituents $[1,2]$. Special mention deserves their role as wood decay agents since very little species of other groups of organisms are capable to attack recalcitrant substances such as cellulose or lignin. Because of the vital importance of fungi to the well-being of an entire ecosystem, the interaction of fungi with the organic and inorganic substrate should be traced.

Over the last few years many articles have been published on the subject of elemental content in sporocarps of wild fungi. Some of them were focused on the perspective of the nutritional skills, or toxicity, when consumed by humans [310] and others tried to settle differences between different species or places $[11,12]$. There are also some recent papers on the subject of the weathering properties of wild mushrooms and their relation with the mineral particles of the soil [13-18]. Some studies have shown a correlation between fungal metal concentrations and point sources of metal pollution such as smelters or roadsides $[19,20]$.

The sporocarps of basidiomycetes have a collection of morphological features, by which we can identify and discriminate the species, and also a short lifetime, generally no more than 7-8 days, although the mycelium may live for many years. Thus, the fungal sporocarps become an advantageous material for the study of the concentrations of the different elements in a wide range of species and, therefore, to track the specific relations with the ecological niche where they live. The hypothesis of our work is that the differences in the absorption rates between fungal species of different lifestyles are a reflection of the substrate from which they feed. The aim of this study is threefold: (1) to compare trace element concentrations between different species and lifestyles; (2) to identify the elements that could be used as lifestyle indicators; (3) to identify the species with a special behaviour in the absorption of certain trace elements. 


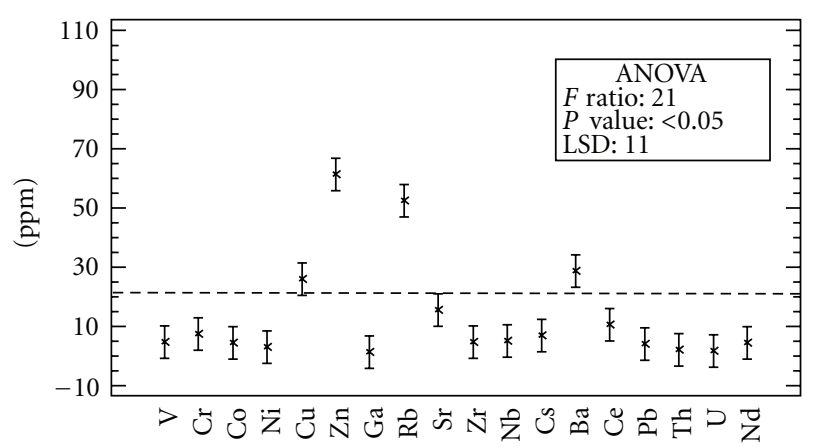

FIGURE 1: Mean value of trace element content averaged over the 18 fungi species studied. The dashed line separates the elements with statistically significant different values following an ANOVA test.

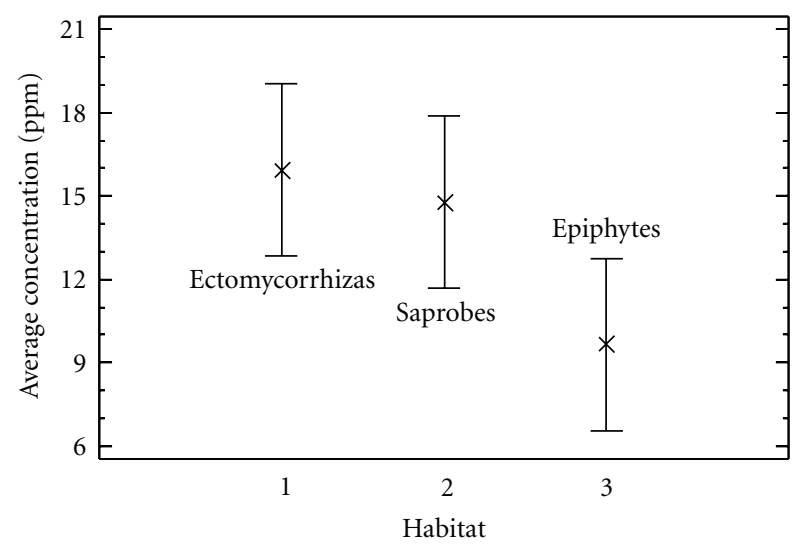

Figure 2: Mean value of trace element concentrations (averaged over the 18 elements measured and the seven species in each lifestyle) for each of the three lifestyles studied. The results of an ANOVA test are also shown.

\section{Material and Methods}

2.1. Sampling and Sample Preparation. Sporocarps were collected from an area with large well-preserved mixed forest of pines and oaks on quartzite acidic soils in the province of Ciudad Real (Spain). We carried out a systematic sampling by which the complete fruiting bodies (cap and stalk) were carefully collected rejecting those very mature or rotten. All samples were brushed and washed with distilled water, then dried at $60^{\circ} \mathrm{C}$ for $48 \mathrm{~h}$, powdered and sieved $(100 \mu \mathrm{m}$ mesh). The resulting powder was stored in hermetic plastic recipient until analysis.

2.2. Species Classification. The classification of the species of mushrooms tested in our study was made according to the systematic keys of Phylum Basidiomycota for European fungi and taking into account the chorological list of species cited in the region of Castilla La Mancha [21]. We have also used the Florule Evolutive des Basidiomycotina du Finisterre by Alain Gerault as a reference of most European species descriptions. These high-quality keys are accessible only via Internet (http://projet.aulnaies.free.fr/Florules/).

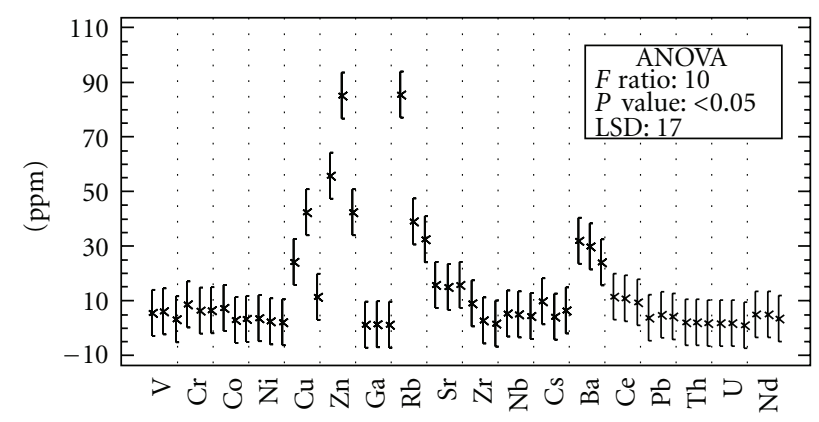

Figure 3: Mean value of each trace element for each of the three lifestyles studied (average over the seven species in each group) following the sequence ectomycorrhizae, saprobes, and epiphytic (from left to right in each element box).

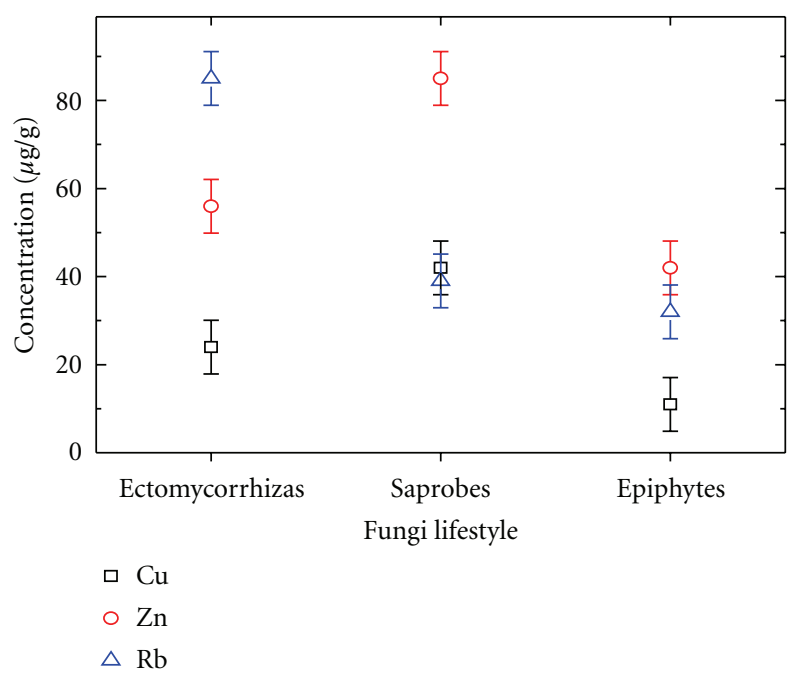

Figure 4: Mean content ( $\left.\mu \mathrm{g} \cdot \mathrm{g}^{-1} \mathrm{DM}\right)$ of $\mathrm{Cu}, \mathrm{Zn}$, and $\mathrm{Rb}$ in each of the three lifestyles studied.

2.3. Metallic Elements Quantification (AC/AQ). The content of eight teen metals was measured by X-ray fluorescence spectrometry. The X-ray intensity was adjusted to obtain a LLD (low limit detection) of around $0.5 \mathrm{ppm}$ for each element. For the use of this analytical method, each powdered sample $(5.0 \mathrm{~g})$ was mixed and homogenized with $0.5 \mathrm{~mL}$ methyl methacrylate (Vacite) and pressed into a pellet of $4.0 \mathrm{~cm}$ in diameter at a pressure of $150 \mathrm{kN}$. X-ray measurements were performed on the pellet samples using a wavelength dispersive X-ray fluorescence spectrometer (PHILIPSPW2404 Pananalytical, Magix-Pro model) equipped with logging data software. The concentration of each metal is expressed in $\mu \mathrm{g} \cdot \mathrm{g}^{-1}$ (dry weight basis). In our work the spectrometer was subjected to a standardized calibration using 12 known elemental concentration standards supplied by the manufacturer. The exposition time to X-ray of the samples was calculated to provide errors below $2 \%$ in ten repeats of the same sample. Pure quartzite ground sand $\left(\mathrm{SiO}_{2}\right)$ was used as blank. Regarding the matrix effect, both 

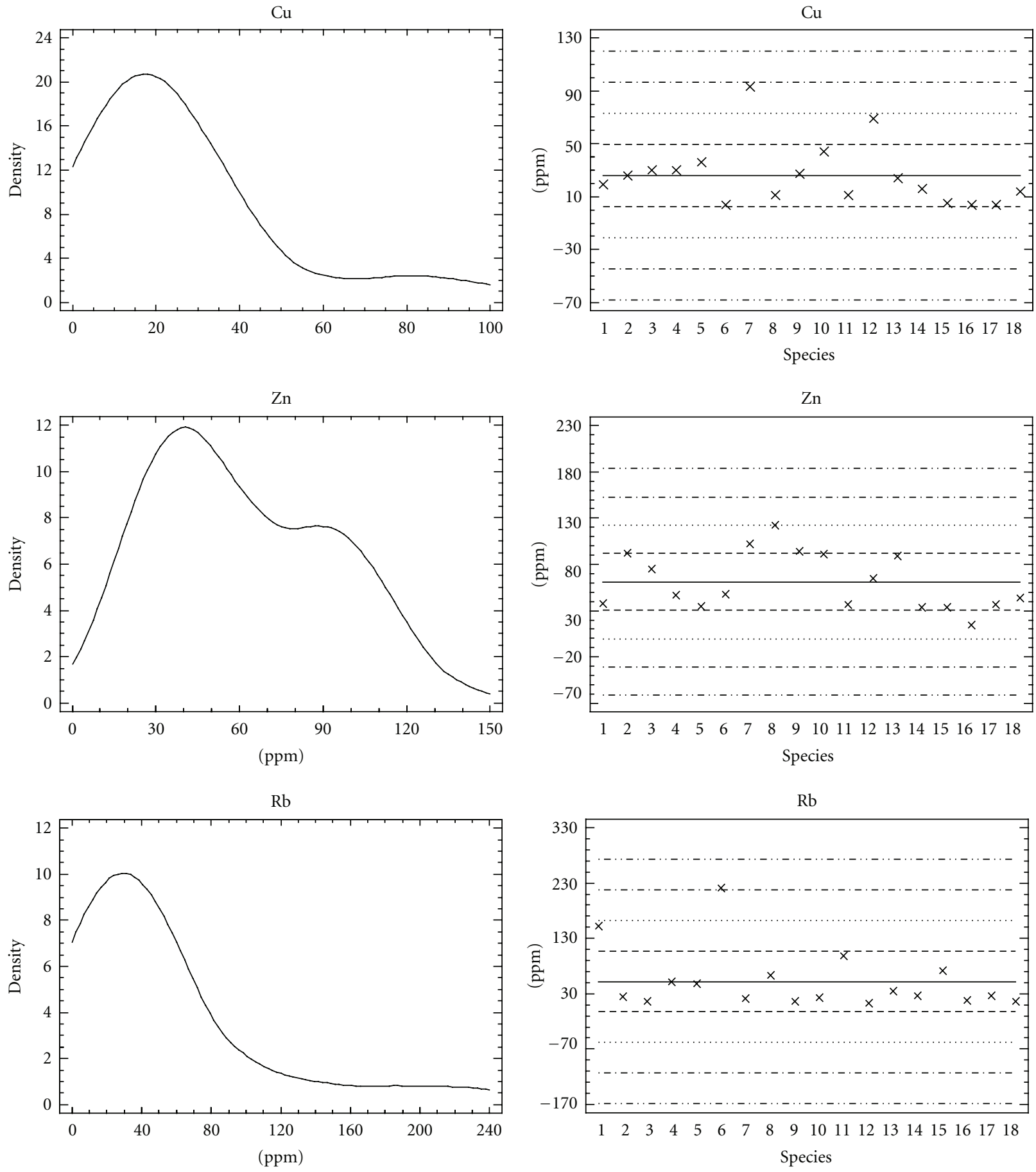

(a)

(b)

FIGURE 5: Nonparametrical density curves (a) and studentized values plots (b) for $\mathrm{Cu}, \mathrm{Zn}$, and Rb. The mean value is depicted by a solid line. The horizontal dashed lines are multiples of the standard deviation. The abscissa tick labels correspond to the species numbered in Table 2.

the standards provided for calibration by the manufacturer and the samples to be analyzed were homogenized and pressed in the same way so that all the (cylindrical) samples had the same physical characteristics. Also, for each sample measurement, the calcination percentage of each species, determined previously, was taken into account.

\section{Statistics and Data Analysis}

The concentration of each metal in each species as well as the total metallic content accumulated by each species were tested with a one-way analysis of variance (ANOVA) in order to establish statistically significant variations in the different 
TABle 1: Content $\left(\mu \mathrm{g} \cdot \mathrm{g}^{-1} \mathrm{DM}\right)$ of trace elements in fungi sporocarps for the 18 species studied. The species are sorted by their lifestyle (Ectomycorrhizae, saprobes, and epiphytic).

\begin{tabular}{|c|c|c|c|c|c|c|c|c|c|c|c|c|c|c|c|c|c|c|c|}
\hline & & $\mathrm{V}$ & $\mathrm{Cr}$ & Co & $\mathrm{Ni}$ & $\mathrm{Cu}$ & $\mathrm{Zn}$ & $\mathrm{Ga}$ & $\mathrm{Rb}$ & $\mathrm{Sr}$ & $\mathrm{Zr}$ & $\mathrm{Nb}$ & Cs & $\mathrm{Ba}$ & $\mathrm{Ce}$ & $\mathrm{Pb}$ & Th & $\mathrm{U}$ & $\mathrm{Nd}$ \\
\hline \multirow{6}{*}{ Ectomycorrhizal } & 1-Amanita phalloides (Fr.)Link & 9 & 14 & 3 & 6 & 19 & 38 & 2 & 152 & 16 & 26 & 6 & 8 & 34 & 10 & 3 & 3 & 2 & 6 \\
\hline & 2- Hebeloma sinapizans (Paulet: Fr.) G. & 4 & 6 & 3 & 2 & 26 & 92 & 1 & 24 & 15 & 3 & 5 & 3 & 30 & 8 & 3 & 2 & 1 & 4 \\
\hline & 3- Lactarius zugazae & 4 & 6 & 3 & 5 & 30 & 75 & 1 & 16 & 17 & 2 & 4 & 3 & 29 & 10 & 4 & 2 & 1 & 4 \\
\hline & 4- Paxillus involutus (Batsch.:Fr.)Fr. & 6 & 6 & 24 & 2 & 30 & 47 & 1 & 51 & 15 & 6 & 5 & 5 & 31 & 14 & 5 & 2 & 1 & 4 \\
\hline & 5- Russula delica Fr. & 5 & 10 & 3 & 4 & 36 & 35 & 1 & 48 & 15 & 9 & 5 & 8 & 32 & 13 & 5 & 2 & 2 & 5 \\
\hline & 6- Suillus bellini (Inzenga)Kuntze & 5 & 9 & 7 & 4 & 4 & 48 & 1 & 221 & 16 & 7 & 6 & 12 & 35 & 14 & 2 & 2 & 2 & 5 \\
\hline \multirow{6}{*}{ Saprobe } & 7- Clitocybe maxima Fr.:Fr. & 15 & 7 & 3 & 3 & 93 & 102 & 1 & 21 & 15 & 2 & 5 & 5 & 30 & 11 & 4 & 2 & 4 & 3 \\
\hline & 8- Entoloma lividum (Bull.)Quél. & 5 & 6 & 2 & 2 & 11 & 122 & 1 & 64 & 14 & 1 & 5 & 3 & 26 & 8 & 3 & 2 & 1 & 3 \\
\hline & 9- Lepista inversa (Scop).Pat & 5 & 5 & 3 & 2 & 27 & 94 & 1 & 16 & 15 & 1 & 5 & 3 & 32 & 12 & 3 & 2 & 1 & 7 \\
\hline & 10- Lepista nuda (Bull.:Fr.)Cooke & 4 & 6 & 3 & 2 & 44 & 91 & 1 & 23 & 15 & 2 & 5 & 2 & 29 & 7 & 5 & 2 & 1 & 3 \\
\hline & 11- Lycoperdon perlatum Pers.:Pers & 4 & 11 & 3 & 4 & 11 & 37 & 1 & 98 & 15 & 8 & 4 & 7 & 35 & 14 & 7 & 2 & 2 & 9 \\
\hline & 12- Macrolepiota procera (Scop.:Fr.)S. & 3 & 5 & 3 & 1 & 69 & 65 & 1 & 12 & 15 & 2 & 4 & 4 & 26 & 13 & 4 & 2 & 1 & 4 \\
\hline \multirow{6}{*}{ Epiphytic } & 13-Agrocybe aegerita (Brig.)Fayod & 2 & 6 & 3 & 2 & 24 & 89 & 1 & 35 & 15 & 2 & 5 & 5 & 27 & 9 & 4 & 2 & 1 & 4 \\
\hline & 14-Armillaria mellea (Vahl.:Fr.)P. K. & 3 & 6 & 3 & 2 & 16 & 34 & 1 & 27 & 14 & 2 & 5 & 9 & 29 & 8 & 4 & 2 & 1 & 3 \\
\hline & 15- Gymnopilus spectabilis (Fr.)Singer & 4 & 9 & 4 & 2 & 5 & 34 & 1 & 72 & 14 & 1 & 4 & 11 & 21 & 9 & 4 & 1 & 1 & 4 \\
\hline & 16- Hericium erinaceus (Bull.:Fr:)Pers & 3 & 7 & 3 & 2 & 4 & 15 & 1 & 18 & 15 & 1 & 4 & 5 & 27 & 6 & 4 & 2 & 1 & 1 \\
\hline & 17- Inonotus hispidus (Bull.:Fr.)P.Karst & 4 & 5 & 3 & 2 & 4 & 37 & 2 & 26 & 21 & 1 & 5 & 4 & 26 & 12 & 5 & 2 & 1 & 5 \\
\hline & 18-Meripilus giganteus (Pers.:Fr.)P.K. & 4 & 7 & 3 & 2 & 14 & 44 & 2 & 17 & 15 & 2 & 4 & 4 & 14 & 11 & 4 & 2 & 1 & 2 \\
\hline
\end{tabular}

TABLE 2: Shapiro-Wilk normality test for $\mathrm{Cu}, \mathrm{Zn}$, and $\mathrm{Rb}$.

\begin{tabular}{lllll}
\hline $\begin{array}{l}\text { Normality test } \\
\text { Shapiro-Wilk-W }\end{array}$ & Statistic & $P$ value & Skewness & Normality \\
\hline $\mathrm{Cu}$ & 0.8 & 0.002 & 3 & Rejected \\
$\mathrm{Zn}$ & 0.9 & 0.7 & 2 & Assumed \\
$\mathrm{Rb}$ & 0.7 & 0.001 & 4 & Rejected \\
\hline
\end{tabular}

elements content between individual species and between different lifestyles. The same test was performed to analyze differences in the total content of the different elements. The density curves for those elements which showed statistical differences were depicted, and a test of normality [22] and a statistical analysis for the identification of outliers was carried out. All statistical analyses were performed using Statgraphics Centurion XV (Statistical Graphics Corp., Rockville, MD, USA).

\section{Results and Discussion}

Although most of the concentration values found by us fall between the thresholds presented by other authors using other analytical procedures [3-10], there are some cases where they do not. Particularly notable are the results of Borovička et al. [23], who give concentrations for some heavy metals several orders of magnitude lower than those found in our analysis $[24,25]$. It must be noticed that, although the spectrometer was thoroughly calibrated, it seems that the methodology of X-ray fluorescence may not be adequate when the concentrations are close to the low detection limit (e.g., heavy metals).
The data of the trace elements measured in our work for each species are given in Table 1. The species have been ranked according to their lifestyle (ectomycorrhizal, saprobe, or epiphytic on wood) and alphabetically within each of these groups. They have also been numbered for a better understanding of the figures. Note that 18 different elements have been measured in 18 different species.

The content of each of the elements in the studied 18 species of mushrooms is around $6 \mu \mathrm{g} \cdot \mathrm{g}^{-1}$ except for $\mathrm{Cu}$, $\mathrm{Zn}, \mathrm{Rb}$, and $\mathrm{Ba}$, where the concentrations are significantly higher. These elements are absorbed in greater quantity than the rest, with contents around $25 \mu \mathrm{g} \cdot \mathrm{g}^{-1}$ for $\mathrm{Cu}$ and $\mathrm{Ba}$ and around $60 \mu \mathrm{g} \cdot \mathrm{g}^{-1}$ for $\mathrm{Zn}$ and $\mathrm{Rb}$ (see Figure 1). The increased concentration of these elements in the fungal biomass is probably due to their presence in greater quantities in the substrate solution, although there might be other additional mechanisms for a selective absorption of these elements, especially for $\mathrm{Cu}$ and $\mathrm{Zn}$, since it has been reported that the levels reached in fungal biomass are species dependent [26]. We have not found statistical differences between the total content of trace elements when the lifestyles are compared. Although the total content in epiphytic mushrooms is clearly lower, this difference does not reach statistical significance (see Figure 2).

When comparing the content of each of the elements between the three different lifestyles (see Figure 3), it can be observed that differences appear only for $\mathrm{Cu}, \mathrm{Zn}$, and $\mathrm{Rb}$. In the case of $\mathrm{Ba}$, the other element with an overall concentration in the fungal biomass statistically higher to the rest, no significant differences were found between lifestyles. $\mathrm{Cu}$ accumulates in saprobe species in higher quantities. Among the epiphytic and ectomycorrhizal species there were not found significant differences for this element. The same 
holds for $\mathrm{Zn}$, although with major differences (Figures 3 and 4). On the other hand, $\mathrm{Rb}$ is more efficiently absorbed by ectomycorrhizal species, without significant differences between the saprophytic and epiphytic groups of species.

Once established that there are clear differences in the absorption of these elements between the three groups of species (ectomycorrhiza, saprobes, and epiphytes), it is convenient to make a more detailed analysis trying to find out the causes of that differential absorption. To this purpose we have performed a test of normality [22] and a search for species with a particular behaviour in the absorption of these elements (statistical "outliers"). The final goal of this analysis is to verify whether that data lies within a normal distribution or not, and, if not, to examine the presence of species that may be considered as outliers. It is assumed that these species have a peculiar absorption for these elements and, therefore, are responsible for breaking the expected normal distribution of the data.

Figure 5 displays the nonparametric density curves for $\mathrm{Cu}, \mathrm{Zn}$, and $\mathrm{Rb}$. The right- hand panels show the corresponding tests for outliers identification with the distribution of each species data (numbered according to Table 1) with respect to the mean (solid line) and standard deviation units (dashed lines). Normality is rejected for $\mathrm{Cu}$ and $\mathrm{Rb}$ (Table 2), with a leftwards shift of the density curve in both cases, which means that there are values high enough above the mean to break normality. The panels on the right-hand side show a different representation of the dispersion of the data in the different species. In the case of $\mathrm{Cu}$, there is a datapoint with value almost three times the standard deviation, which can therefore be considered an outlier. This datapoint corresponds to Clitocybe maxima, a species located within the saprobe group. It seems that the presence of $\mathrm{Cu}$ in fungal biomass is more related to specific absorptive skills of the species than to the concentration of this element in the substrate solution, since we cannot expect a high spatial heterogeneity of the deposits of this element in a forest soil (e.g., from organic waste, excrements, etc.).

The density curve of the data shows that $\mathrm{Zn}$ is set to normal, according to the Shapiro-Wilk test (Table 2); however two modes are hinted, where the smaller one; centered at $95 \mathrm{ppm}$; corresponds to the saprobe group, consistently with the observed significant differences in Figures 3 and 4, and thus confirming that differences between saprobe species and the rest of the lifestyles do exist. It can therefore be concluded that the differences found between the saprobe species and the other groups are based on the physiological characteristics shared by the species of this particular trophic group and not by the presence of outliers. Alonso et al. [26] give values between 130 and $267 \mu \mathrm{g} \cdot \mathrm{g}^{-1}$ in saprobe species of genus Agaricus (A. campestris, A. Macrospores, and A. silvicola). These authors suggest that saprophytic species have more efficient mechanisms to absorb trace elements than ectomycorrhiza ones.

In the case of $\mathrm{Rb}$ the test of normality (Table 2 ) indicates that the data were not normally distributed. In a more detailed analysis (Figure 5) it can be seen that the species Suillus bellini accumulates this element in a much greater amount than the other species (three times the standard deviation), shifting the density curve leftwards and breaking the expected normality. This species can be considered as a statistical outlier with a particular absorptive behaviour. We can assume that the absorption of $\mathrm{Rb}$ is species specific and that it is supported by a particular nutritional physiology not shared by the whole trophic group. The special skills of some ectomycorrhizal species (e.g., Suillus sp.), by attacking mineral particles of soil, may underlie this result.

\section{Conclusions}

The concentrations of the trace elements $\mathrm{Cu}, \mathrm{Zn}$, and $\mathrm{Rb}$ found in the biomass of eighteen species of mushrooms are related to the lifestyle (ectomycorrhiza, saprobe, or epiphytic on wood). $\mathrm{Cu}$ and $\mathrm{Zn}$ accumulate in greater amounts in saprobes species and $\mathrm{Rb}$ reaches higher concentrations in the ectomycorrhiza species group. Further analysis indicates that the species Clitocybe maxima and Suillus bellini act as hyperaccumulators of $\mathrm{Cu}$ and $\mathrm{Rb}$, respectively, and this is crucial in establishing the statistical significance between the trophic groups. Hyperaccumulating species do not appear in the case of $\mathrm{Zn}$ and, therefore, we assume that the differences found between the three lifestyles stem from the peculiarities of the nutritional physiology shared by the species in each group.

\section{References}

[1] V. Wiemken, "Contributions of studies with in vitro culture systems to the understanding of the ectomycorrhizal symbiosis," in Mycorrhiza: Structure, Function, Molecular Biology and Biotechnology, A. Varma and B. Hock, Eds., Springer-Verlag, New York, NY, USA, 1995.

[2] P. E. Courty, M. Buée, A. G. Diedhiou et al., "The role of ectomycorrhizal communities in forest ecosystem processes: new perspectives and emerging concepts," Soil Biology and Biochemistry, vol. 42, no. 5, pp. 679-698, 2010.

[3] D. Mendil, O. D. Uluözlü, E. Hasdemir, and A. Çağlar, "Determination of trace elements on some wild edible mushroom samples from Kastamonu, Turkey," Food Chemistry, vol. 88, no. 2, pp. 281-285, 2004.

[4] N. Dursun, M. M. Özcan et al., "Mineral contents of 34 species of edible mushrooms growing wild in Turkey," Journal of the Science of Food and Agriculture, vol. 86, no. 7, pp. 1087-1094, 2006.

[5] L. Cocchi, L. Vescovi, L. E. Petrini, and O. Petrini, "Heavy metals in edible mushrooms in Italy," Food Chemistry, vol. 98, no. 2, pp. 277-284, 2006.

[6] P. K. Ouzouni, P. G. Veltsistas, E. K. Paleologos, and K. A. Riganakos, "Determination of metal content in wild edible mushroom species from regions of Greece," Journal of Food Composition and Analysis, vol. 20, no. 6, pp. 480-486, 2007.

[7] K. Chudzyński and J. Falandysz, "Multivariate analysis of elements content of Larch Bolete (Suillus grevillei) mushroom," Chemosphere, vol. 73, no. 8, pp. 1230-1239, 2008.

[8] J. J. Falandysz, T. Kunito, R. Kubota et al., "Some mineral constituents of Parasol mushroom (Macrolepiota procera)," Journal of Environmental Science and Health, Part B, vol. 43, pp. 187-192, 2008.

[9] P. Kalač, "Chemical composition and nutritional value of European species of wild growing mushrooms: a review," Food Chemistry, vol. 113, no. 1, pp. 9-16, 2009. 
[10] P. Kalač, “Trace element contents in European species of wild growing edible mushrooms: a review for the period 20002009," Food Chemistry, vol. 122, no. 1, pp. 2-15, 2010.

[11] G. Tyler, "Metal accumulation by wood-decaying fungi," Chemosphere, vol. 11, no. 11, pp. 1141-1146, 1982.

[12] J. Vetter, "Mineral composition of basidiomes of Amanita species," Mycological Research, vol. 109, no. 6, pp. 746-750, 2005.

[13] R. Landeweert, E. Hoffland, R. D. Finlay, T. W. Kuyper, and N. Van Breemen, "Linking plants to rocks: ectomycorrhizal fungi mobilize nutrients from minerals," Trends in Ecology and Evolution, vol. 16, no. 5, pp. 248-254, 2001.

[14] E. Hoffland, T. W. Kuyper, H. Wallander et al., "The role of fungi in weathering," Frontiers in Ecology and the Environment, vol. 2, pp. 258-264, 2004.

[15] G. M. Gadd, Fungi in Biogeochemical Cycles, Cambridge University Press, Cambridge, UK, 2006.

[16] G. M. Gadd, "Global biogeochemical cycling: fungi and their role in the biosphere," in Encyclopedia of Ecology, Elsevier, Amsterdam, The Netherlands, 2007.

[17] R. Amundson, D. D. Richter, G. S. Humphreys, E. G. Jobbágy, and J. Gaillardet, "Coupling between biota and earth materials in the critical zone," Elements, vol. 3, no. 5, pp. 327-332, 2007.

[18] L. van Schöll, T. W. Kuyper, M. M. Smits, R. Landeweert, E. Hoffland, and N. V. Breemen, "Rock-eating mycorrhizas: their role in plant nutrition and biogeochemical cycles," Plant and Soil, vol. 303, no. 1-2, pp. 35-47, 2008.

[19] J. D. McCreight and D. B. Schroeder, "Cadmium, lead and nickel content of Lycoperdon perlatum Pers. in a roadside environment," Environmental Pollution, vol. 13, no. 4, pp. 265268, 1977.

[20] R. Bargagli and F. Baldi, "Mercury and methyl mercury in higher fungi and their relation with the substrata in a cinnabar mining area," Chemosphere, vol. 13, no. 9, pp. 1059-1071, 1984.

[21] F. D. Calonge, G. Moreno et al., "Flora Micológica de Castilla La Mancha. Situación actual y conservación de los hongos del bosque," in Memoria Final (2004-2007), Hernandez-Crespo, Ed., Real Jardín Botánico CSIC, Madrid, Spain, 2008.

[22] S. S. Shapiro and M. B. Wilk, "An analysis of variance test for normality (complete samples)," Biometrika, vol. 52, pp. 591611, 1965.

[23] J. Borovička, J. Kubrová, J. Rohovec, Z. Řanda, and C. E. Dunn, "Uranium, thorium and rare earth elements in macrofungi: what are the genuine concentrations?" BioMetals, vol. 24, no. 5, pp. 837-845, 2011.

[24] J. A. Campos, N. A. Tejera, and C. J. Sánchez, "Substrate role in the accumulation of heavy metals in sporocarps of wild fungi," BioMetals, vol. 22, no. 5, pp. 835-841, 2009.

[25] J. A. Campos, "Nutrients and trace elements content of wood decay fungi isolated from oak (Quercus ilex)," Biological Trace Element Research, vol. 144, no. 1-3, pp. 1370-1380, 2011.

[26] J. Alonso, M. A. García, M. Pérez-López, and M. J. Melgar, "The concentrations and bioconcentration factors of copper and zinc in edible mushrooms," Archives of Environmental Contamination and Toxicology, vol. 44, no. 2, pp. 180-188, 2003. 

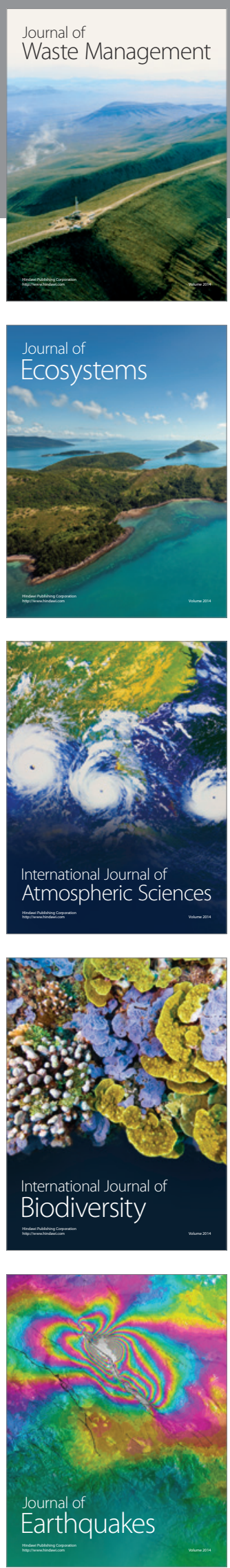
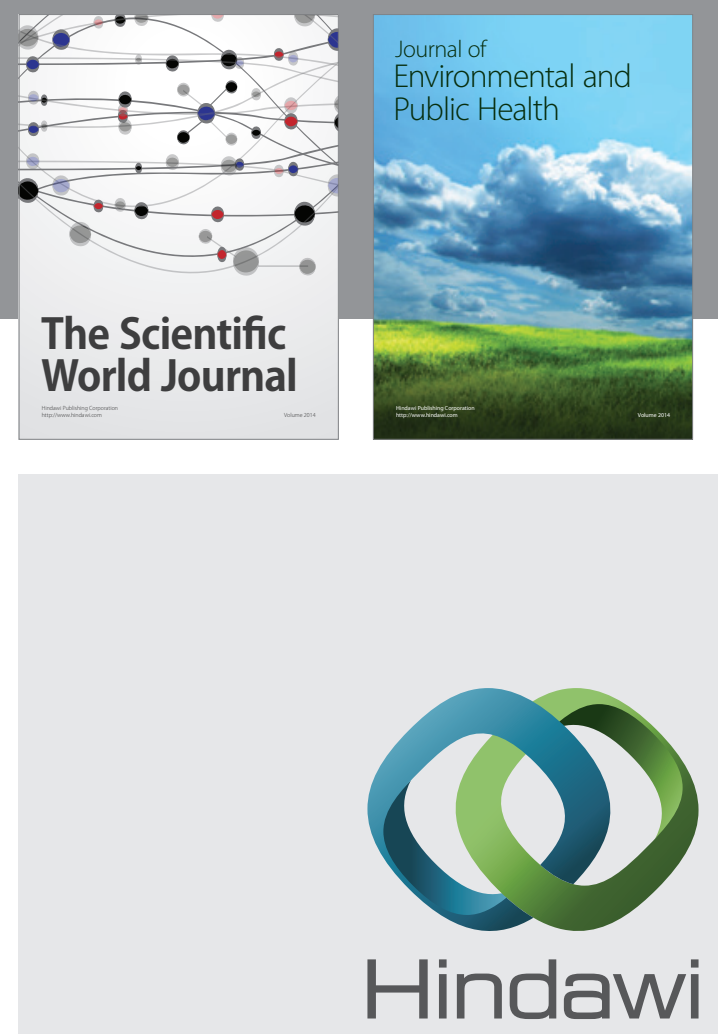

Submit your manuscripts at

http://www.hindawi.com
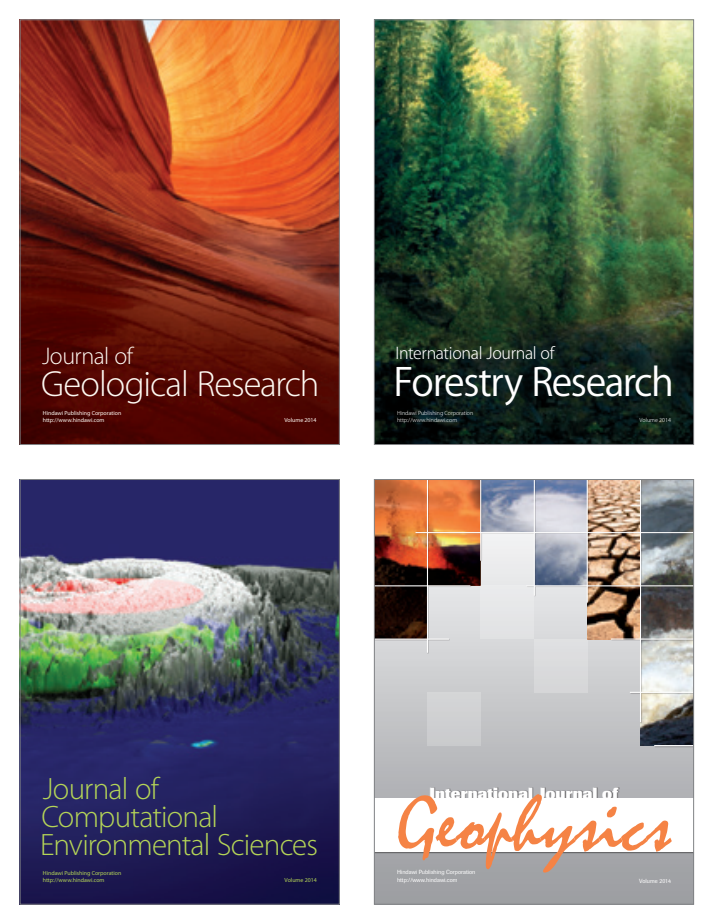
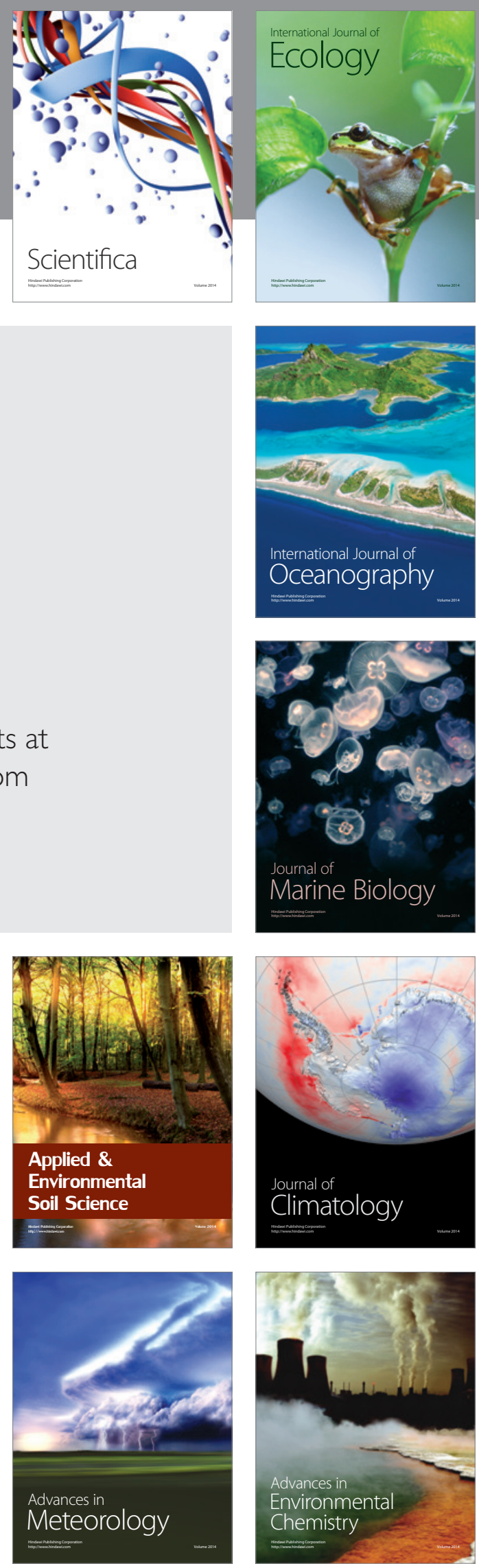